\title{
A SINGLE TRAINING SESSION OF VISUAL CHOICE REACTION TIME AFTER MILD STROKE: A PROOF OF CONCEPT
}

original paper

(c) Wroclaw University of Health and Sport Sciences

DOI: https://doi.org/10.5114/hm.2021.106168

\section{TAMISE AGUIAR CAIRES ${ }^{1}$, GUSTAVO JOSÉ LUVIZUTTO ${ }^{1}$, PAULA CÍNTIA DOS SANTOS VIEIRA ${ }^{1}$, GABRIEL JABLONSKI ${ }^{2}$, RODRIGO BAZAN ${ }^{3}$, ADRIANO DE OLIVEIRA ANDRADE ${ }^{2}$, LUCIANE APARECIDA PASCUCCI SANDE DE SOUZA ${ }^{1}$}

${ }^{1}$ Department of Applied Physical Therapy, Federal University of Triângulo Mineiro, Uberaba, Brazil

${ }^{2}$ Centre for Innovation and Technology Assessment in Health, Faculty of Electrical Engineering, Federal University of Uberlândia, Uberlândia, Brazil

${ }^{3}$ Department of Neurology, Botucatu Medical School, São Paulo State University, Botucatu, Brazil

\section{ABSTRACT}

Purpose. Visual choice reaction time can be measured in reaching, which is an important task to investigate after stroke owing to its high clinical importance in activities of daily living. The study aim was to evaluate the visual choice reaction time during reaching tasks in the ipsilateral and contralateral spaces before and after a single training session of choice reaction time in patients after a mild stroke.

Methods. The cross-sectional study involved 7 individuals after a mild stroke. The visual choice reaction time was evaluated during reaching in the affected and unaffected sides in the ipsilateral and contralateral spaces. All individuals trained the choice reaction time during a functional reaching task in a single session. In the training, 6 circles were used in a randomized sequence in 5 blocks, with 10 stimuli per block, for a total of 50 repetitions.

Results. There was a significant reduction in the choice reaction time for the unaffected side in the ipsilateral space after training $(p=0.041)$. The other task conditions did not show a statistical difference, but a clinical relevance based on Cohen's $d$ $(d>0.60)$.

Conclusions. A single training session can decrease the choice reaction time for the affected side during tasks in the ipsilateral space after a mild stroke.

Key words: stroke, choice reaction time, electromyography

\section{Introduction}

Visual choice reaction time (CRT) is measured with a set of stimuli and responses, with each stimulus being associated with a particular response [1, 2]. Stroke patients present a delay in CRT owing to slower motor responses [3-5], changes in muscular activation [6], and deficits in response selection [7], even in the absence of clinical motor deficits.

Visual CRT can be modified by the type of motor task (implicit or explicit), complexity of the task [3, 8], variability of the task (constant, blocked, and random tasks) [9], and training. Stewart et al. [10] show that a single training session can change the response time in a visual CRT task in stroke patients. In another study with a single session, the authors observed a slower performance in stroke patients than in control subjects in a condition with randomized tasks of high complexity [8].

Visual CRT can be measured in different activities, such as reaching, which is an important activity to investigate after stroke owing to its high clinical importance in activities of daily living [11]. Visual CRT response can be different between reaching tasks per-

Correspondence address: Gustavo José Luvizutto, Department of Applied Physical Therapy, Institute of Health Sciences, Federal University of Triângulo Mineiro, Rua Vigário Carlos, 100 - Sala 319 - $3^{\circ}$ andar - Bairro Abadia, CEP: 38025350 - Uberaba-MG, Brazil, e-mail: gluvizutto@gmail.com

Received: August 25, 2020

Accepted for publication: January 18, 2021

Citation: Caires TA, Luvizutto GJ, Vieira PCS, Jablonski G, Bazan R, Andrade AO, de Souza LAPS. A single training session of visual choice reaction time after mild stroke: a proof of concept. Hum Mov. 2022;23(2):21-27; doi: https://doi.org/10.5114/ hm.2021.106168. 
T.A. Caires et al., Training session of visual choice reaction time after stroke

formed in the ipsilateral and contralateral spaces. Reaching in the contralateral space compared with that in the ipsilateral space has a longer latency, lower speed, and less precision [12]. Therefore, reaching tasks in the contralateral space are more complex [13], and other studies have verified that random practice in both spaces facilitates the consolidation of motor memory [14] and a reduction in reaction time [9]. However, the exact significance of this learning effect is unclear in individuals after stroke [15]. Therefore, a factor not yet investigated by the studies of reaching tasks is: Can a single training session of visual CRT modify the CRT values in both the regions of space?

Thus, the aim of the study was to evaluate visual CRT during reaching tasks in the ipsilateral and contralateral spaces before and after a single training session of CRT in patients after a mild stroke. The main hypothesis of this study was that the visual CRT during reaching would decrease after a single treatment session in both spaces.

\section{Material and methods}

\section{Study design}

A cross-sectional study was performed among individuals diagnosed with stroke. The data collection was carried out at the Laboratory of Biomechanics and Motor Control of Federal University of Triângulo Mineiro from March 2018 to February 2019.

\section{Subjects}

The eligibility criteria for participation in the study were: (i) mild stroke in the chronic stage, up to 1 year after ictus, confirmed by medical records and neuroimaging examinations; (ii) age > 18 years; (iii) a score of up to +1 (equivalent to minimum hypertonia) in the Modified Ashworth Scale (MAS) [16]; (iv) a score of > 30 on the Fugl-Meyer Scale (items related to upper limb function - mild stroke); (v) a Mini Mental State Examination (MMSE) score of $\geqslant 20$ points for individuals with 1-4 years of education, $\geq 25$ points for individuals with $5-8$ years of education, $\geq 26.5$ points for individuals with 9-11 years of education, and $\geq 29$ points for individuals with more than 11 years of education [17]; (vi) absence of other neurologic diseases, such traumatic brain injury, and any orthopaedic or rheumatic disorders that could interfere with the execution of the protocol.

\section{Variable assessment}

(a) MMSE: This scale was used to exclude individuals with cognitive impairment. It has a maximum score of 30 [18]. The cut-off points applied were those corresponding to the educational level of the participants [17].

(b) Fugl-Meyer Scale: It was used to investigate sensory-motor recovery. Only items related to upper limb function were considered, with a maximum score of 126 points [19].

(c) MAS: This scale served for the quantification of muscular tone. The scores range from 0 to 5 [20].

\section{Outcome measures}

For CRT evaluation, the individuals were seated in a chair with adjustable height, with their hips, knees, and ankles at $90^{\circ}$ of flexion, their shoulders at $10-15^{\circ}$ of flexion, their elbows at $75-90^{\circ}$ of flexion, and their forearms pronated. To avoid compensatory movements, the trunk was stabilized at the $7^{\text {th }}$ thoracic vertebra by using a chest brace. A monitor was placed in front of the individual at a distance dependent on the upper limb length, which was measured from acromion to the distal phalanx of the index finger, with a measuring tape. The seat height was adjusted to $100 \%$ of the lower limb length, which was measured from the lateral knee joint to the floor in a straight line with the subject standing barefoot. The centre of the monitor height was adjusted to $75 \%$ of the subject's shoulder height, which was defined as the distance from the shoulder marker to the floor with the participant sitting in the standardized position (Figure 1A). The individual had to reach in the ipsilateral or contralateral spaces in response to the visual stimulus, as quickly and accurately as possible, and return to the anatomic initial position at the end. The visual stimulus, represented by a white circle, lasted 5 seconds and could appear at $5,6,7,8$, or 9 seconds in a randomized sequence. The circles used for the evaluation were only circles 3 and 4 (Figure 1B).

The electromyographic (EMG) signal of the anterior deltoid was used to determine the onset of the muscle response analysed. The EMG signals were recorded with a Delsys Trigno $\mathrm{TM}^{\circledR}$ wireless telemetry sensor at $2000 \mathrm{~Hz}$, in accordance with the Surface Electromyography for Non-Invasive Assessment of Muscles protocol [21]. A photodiode was applied to synchronize the EMG signal with the visual stimulus.

CRT was calculated in milliseconds by the difference between the photodiode signal and EMG activ- 
A

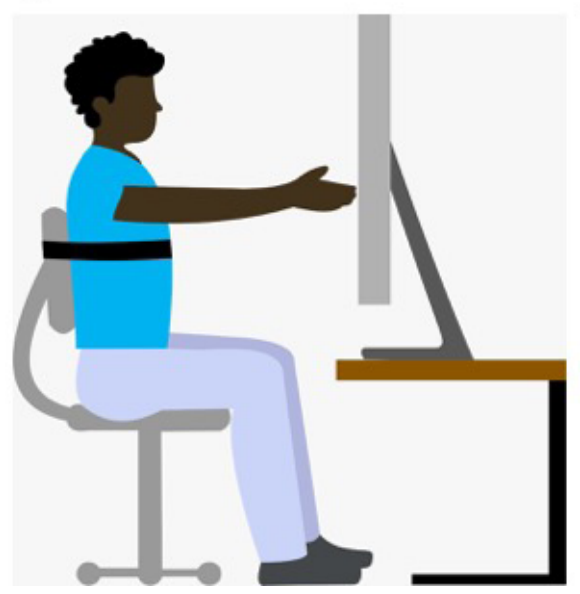

B

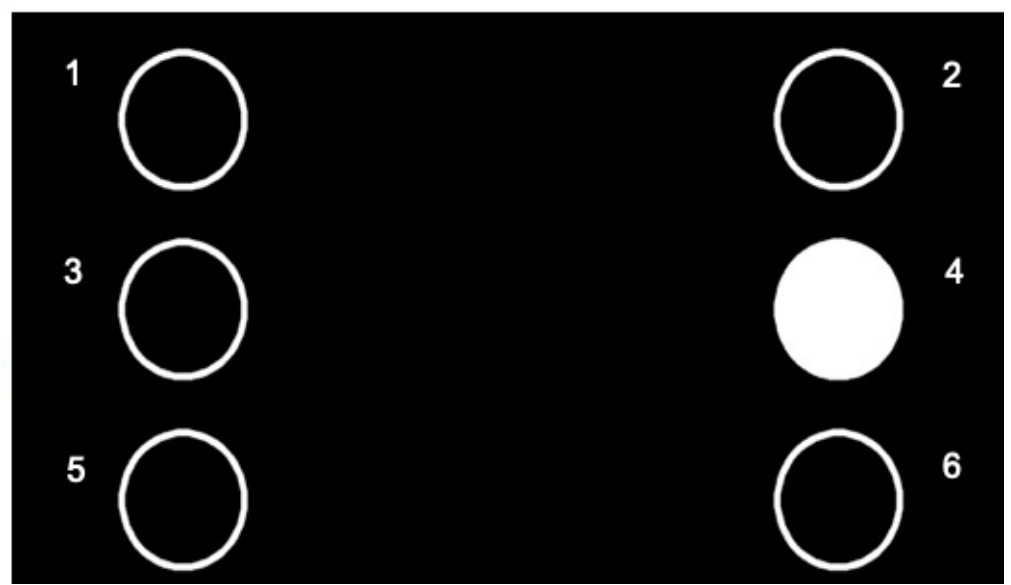

Figure 1. (A) The individual's position during the evaluation and the choice reaction time training session (B) representation of a visual stimulus on the screen

\section{Stimulus}
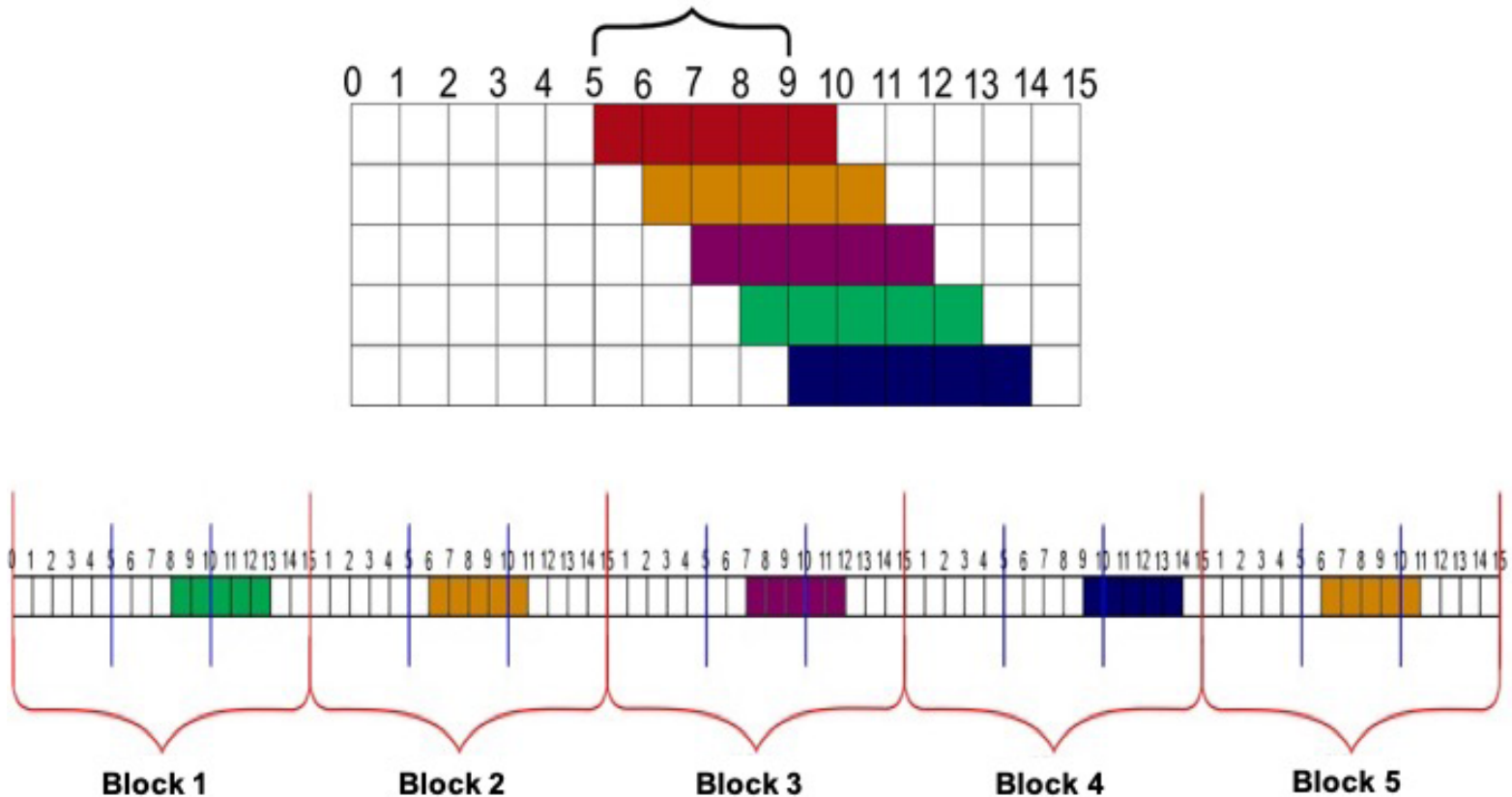

Figure 2. Configuration of choice reaction time training

ity in 4 reaching tasks: (1) reaching with the affected side in the ipsilateral space; (2) reaching with the unaffected side in the ipsilateral space; (3) reaching with the affected side in the contralateral space; and (4) reaching with the unaffected side in the contralateral space.

All of the assessment tools were administered by a physiotherapist. All participants included in the evaluation participated in a weekly rehabilitation (physical therapy and occupational therapy) programme in accordance with the American guidelines for rehabilitation in stroke patients [22].

\section{Interventions}

Each individual had to reach in the ipsilateral or contralateral spaces in response to the visual stimulus, as quickly and accurately as possible, 5 minutes after CRT evaluation. In the training, all 6 circles were used in a randomized sequence in 5 blocks, with 10 stimuli per block, for a total of 50 repetitions [23] (Figure 2). The training was conducted with both upper limbs in a single session. After the training, the individual was reassessed by the same CRT evaluation. 


\section{HUMAN MOVEMENT}

T.A. Caires et al., Training session of visual choice reaction time after stroke

\section{Sample size}

The sample size was calculated to match the primary outcome with sample size estimation. On the basis of treatment effect change and 1.10 of effect size, with a fixed alpha error of 0.05 and beta error of 0.20 , 7 patients constituted the necessary sample. The sample size calculation was performed with the $G^{*}$ Power 3.1.3 software.

\section{Statistical methods}

Descriptive statistics were used for sample characterization. The CRT variables presented a normal distribution (Shapiro-Wilk test), and Student's $t$-test for dependent variables (CRT) served to compare the preand post-intervention results for both sides in each space. Pearson's correlation test was applied used to assess the associations between the CRT on the affected and unaffected sides, as well as the MMSE, MAS, and Fugl-Meyer scores. The associations were considered significant at the value of $p<0.05$. In addition, Cohen's $d$ test was used to analyse the effect size and clinical relevance $(d<0.5$, small clinical relevance; $d$ of $0.5-0.79$, moderate clinical relevance; $d>0.8$, large clinical relevance) [24], and kurtosis (k) analysis was performed to assess data variability. The data were analysed with the IBM SPSS Statistics ${ }^{\circledR}$ version 21 and Prism 7 software.

\section{Ethical approval}

The research related to human use has complied with all the relevant national regulations and institutional policies, has followed the tenets of the Declaration of Helsinki, and has been approved by the authors' institutional review board.

\section{Informed consent}

Informed consent has been obtained from all individuals included in this study.

\section{Results}

A total of 20 patients were recruited, and 7 were included in this study (Figure 3).

The convenience sample was composed of 7 individuals with stroke (Table 1 ).

There was a significant reduction in CRT for the unaffected side in the ipsilateral space after training (mean difference [MD]: -0.048 ; CI: -0.096 to -0.011 ; $p=0.041$ ). There was no significant difference in CRT for the affected side in the ipsilateral space after train-

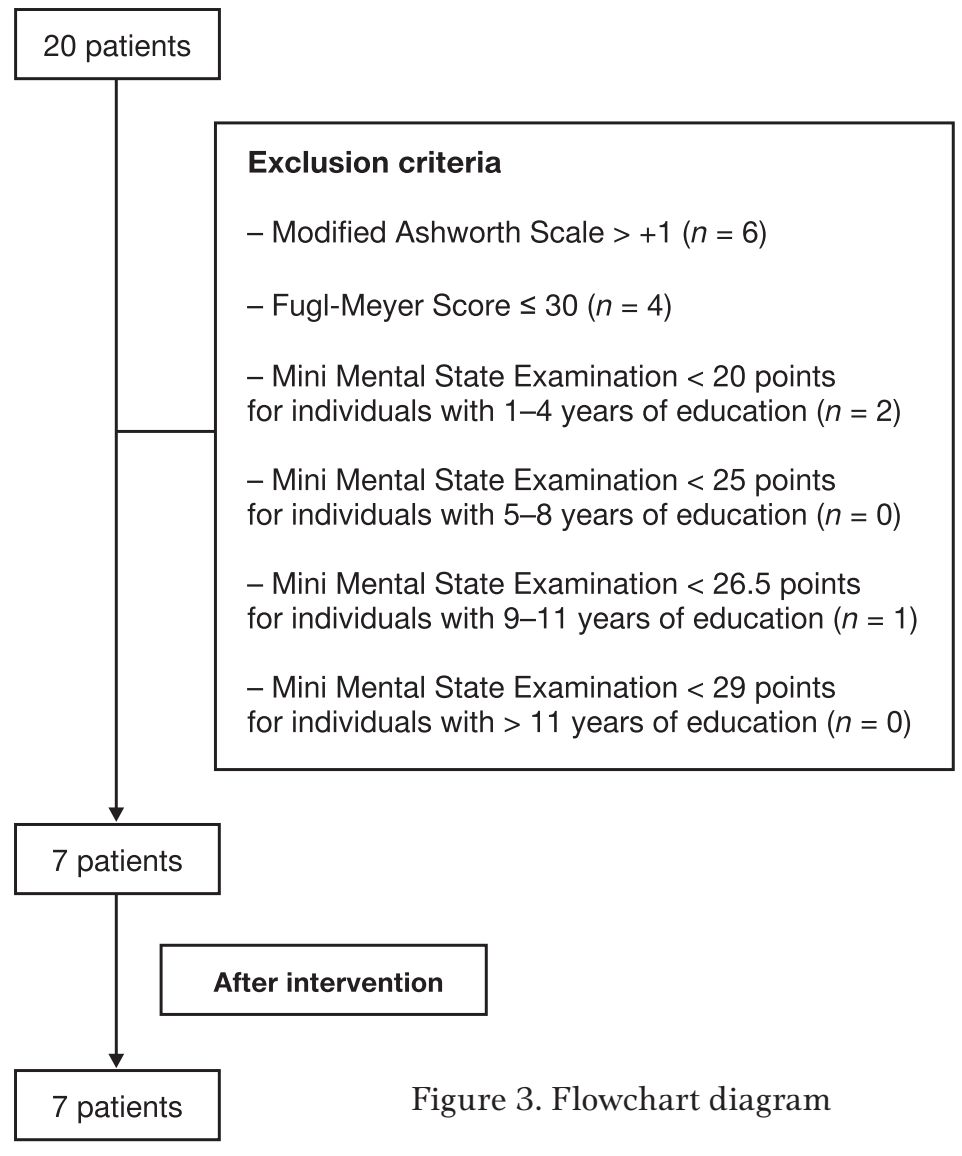

Table 1. Experimental group characteristics

\begin{tabular}{|c|c|}
\hline Variables & Value \\
\hline \multicolumn{2}{|l|}{ Gender $^{1}$} \\
\hline Female & 2 \\
\hline Male & 5 \\
\hline $\operatorname{Age}^{2}$ (years) & $63.14 \pm 3.48$ \\
\hline \multicolumn{2}{|l|}{ Type of stroke ${ }^{1}$} \\
\hline Ischemic & 6 \\
\hline Haemorrhagic & 1 \\
\hline Time of stroke ${ }^{2}$ (days) & $224.43 \pm 111.25$ \\
\hline \multicolumn{2}{|l|}{ Upper limb affected $^{1}$} \\
\hline Right & 3 \\
\hline Left & 4 \\
\hline Mini Mental State Examination ${ }^{2}$ & $23.71 \pm 5.17$ \\
\hline Fugl-Meyer Scale ${ }^{2}$ & $121.14 \pm 8.04$ \\
\hline Ashworth $^{3}$ (scores: 1/0) & $2 / 5$ \\
\hline \multicolumn{2}{|c|}{$\begin{array}{l}3 \text { - ratio between the number of participants with score } \\
1 \text { and } 0\end{array}$} \\
\hline
\end{tabular}




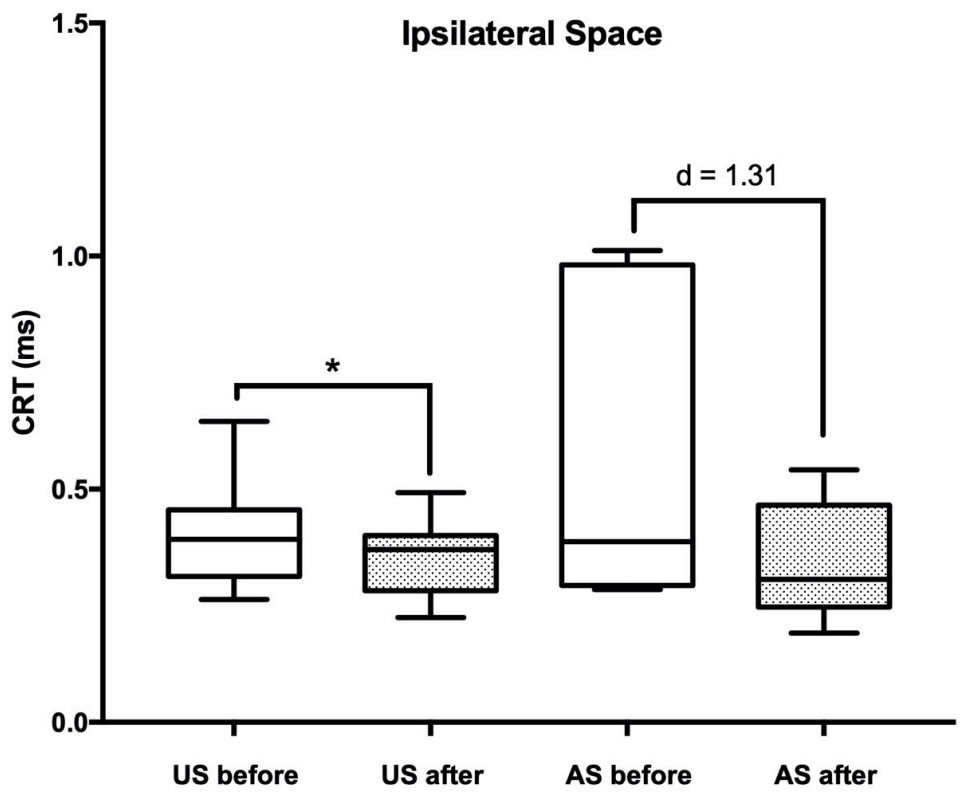

CRT - choice reaction time

US - unaffected side

AS - affected side

* Significant reduction in CRT for the unaffected side in the ipsilateral space after training $(p=0.041)$

Figure 4 . Choice reaction time before and after training for the affected and unaffected sides in the ipsilateral space

\section{Contralateral Space}

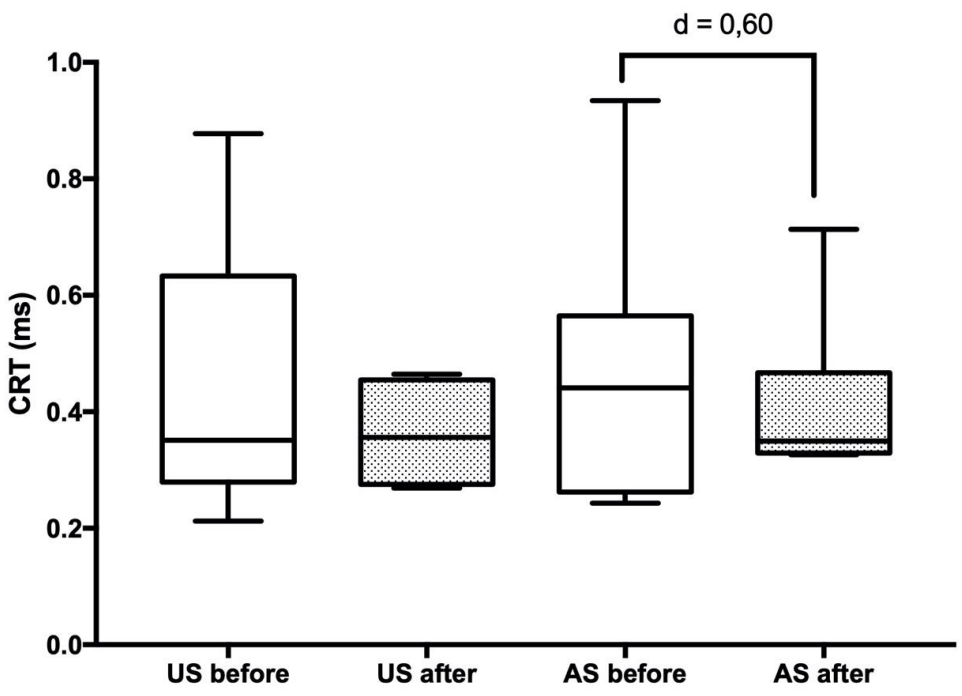

CRT - choice reaction time

US - unaffected side

AS - affected side

Figure 5. Choice reaction time before and after training for the affected and unaffected sides in the contralateral space ing (MD: -0.239 ; CI: -0.510 to 0.03; $p=0.074$ ) (Figure 4), but Cohen's $d$ test showed high clinical relevance $(d=1.31)$ in this condition. CRT variability decreased on both sides in the ipsilateral space: $\mathrm{k}_{\text {before }}=2.19$ and $\mathrm{k}_{\mathrm{after}}=0.26$ for the unaffected side; $\mathrm{k}_{\mathrm{before}}=-1.98$ and $k_{\text {after }}=-0.29$ for the affected side.

There was no significant difference in CRT values for both limbs in the contralateral space (MD: 0.04; CI: -0.06 to $0.159 ; p=0.310$ ) and the ipsilateral space (MD: -0.07 ; CI: -0.248 to $0.104 ; p=0.347$ ) (Figure 5). Cohen's $d$ test showed moderate clinical relevance $(d=0.60)$ for the reduction in CRT on the affected side in the contralateral space. CRT variability values for the unaffected side were $\mathrm{k}_{\text {before }}=1.16$ and $\mathrm{k}_{\mathrm{after}}=-2.55$, and the variability decreased on the affected side in the contralateral space $\left(\mathrm{k}_{\text {before }}=4.30\right.$ and $\left.\mathrm{k}_{\mathrm{after}}=2.11\right)$.

\section{Discussion}

The main findings of the present study were as follows: (1) In the ipsilateral space, differences in the visual CRT values of the unaffected side were observed before and after training; although the differences were not statistically significant, a high clinical relevance was determined in this condition. (2) In the contralateral space, a moderate clinical relevance was indicated in the visual CRT values of the affected and unaffected sides.

De Paiva Silva et al. [25] highlighted that movement direction influenced both movement planning and execution. Reaching over the midline and the presence of a choice increased the complexity of the task. Such complexity needs to be considered during the evaluation and training of individuals after stroke [26].

Why did the visual CRT values for the unaffected limb decrease after a single session in the ipsilateral space but not in the contralateral space? The medians of the visual CRT for both sides were similar, but there was greater variability before training for the unaffected limb. After visual CRT treatment, the variability of the visual CRT values decreased, which could contribute to the high clinical relevance. The visual CRT for the unaffected limbs can be similar to that in healthy limbs despite the number of non-crossing motor fibres in the motor cortex [27]. The visual CRT reduction can be explained by enhanced cognitive activity during random practice, higher engagement in inter-task elaborative processing, and the need to reconstruct an action plan after each trial [28].

A single training session cannot be sufficient to reduce visual CRT in complex tasks, such as reaching in the contralateral space. In our study, visual CRT was 
T.A. Caires et al., Training session of visual choice reaction time after stroke

bigger during reaching in the contralateral space, with higher variability. This finding supports the hypothesis that contralateral movements are more complex and thus lead to longer CRTs owing to the greater need for spatial orientation, body scheme development, and bilateral coordination [29-31].

Klapp [32] suggested that planning took longer for more complex movements, which is reflected in CRT. Therefore, it seems impossible to change visual CRT in the contralateral space during explicit tasks with only a single session [32]; however, in another study that used a single session, the authors observed that individuals were able to learn an implicit motor task, with a decrease in reaction time [8]. After practice, implicit motor learning is evidenced by the fact that participants generally respond significantly faster to sequenced stimuli than to randomly presented ones, without being able to explicitly recall or recognize this learned sequence [33]. The length and intensity of the treatments reported in the literature were not defined [13]. Studies have shown that one session can promote improvement in the motor system. For example, high-intensity training can increase motor learning and prehension ability after stroke [34].

Considering these interesting findings in this proof of concept, we emphasize the importance of a large sample size and a visual CRT test after 24 hours of training. This study brings an important contribution to research on rehabilitation after stroke, which may infer that a random and distributed single training session reduces visual CRT in the ipsilateral space at the unaffected side, but the data of clinical relevance showed also visual CRT reduction in the contralateral space at the affected side. These findings must be reinforced through multicentre randomized clinical trials to explore not only the performance, but also the learning effects after visual CRT training.

\section{Conclusions}

Visual CRT decreases on the unaffected side in ipsilateral space after a single CRT training session in individuals after a mild stroke.

\section{Disclosure statement}

No author has any financial interest or received any financial benefit from this research.

\section{Conflict of interest}

The authors state no conflict of interest.

\section{Funding}

Sources of funding received for the work: National Council for Scientific and Technological Development (CNPq), Coordination of Improvement of Higher Education Personnel (CAPES, program CAPES/DFATD88887.159028/2017-00), Foundation for Research Support of the State of Minas Gerais (FAPEMIG, APQ00942-17), and Foundation for Research Support of the Federal District (FAPDF). A.O. Andrade is a Fellow of CNPq, Brazil (305223/2014-3).

\section{References}

1. Pullman SL, Watts RL, Juncos JL, Chase TN, Sanes JN. Dopaminergic effects on simple and choice reaction time performance in Parkinson's disease. Neurology. 1988;38(2):249-254; doi: 10.1212/wnl.38.2.249.

2. Godefroy O, Spagnolo S, Roussel M, Boucart M. Stroke and action slowing: mechanisms, determinants and prognosis value. Cerebrovasc Dis. 2010;29(5):508-514; doi: 10.1159/000297968.

3. Cauraugh J, Kim S. Stroke motor recovery: active neuromuscular stimulation and repetitive practice schedules. J Neurol Neurosurg Psychiatry. 2003;74(11): 1562-1566; doi: 10.1136/jnnp.74.11.1562.

4. Kubicki A, Petrement G, Bonnetblanc F, Ballay Y, Mourey F. Practice-related improvements in postural control during rapid arm movement in older adults: a preliminary study. J Gerontol A Biol Sci Med Sci. 2012;67(2):196-203; doi: 10.1093/gerona/glr148.

5. Bleyenheuft Y, Gordon AM. Precision grip in congenital and acquired hemiparesis: similarities in impairments and implications for neurorehabilitation. Front Hum Neurosci. 2014;8:459; doi: 10.3389/fnhum.2014.00459.

6. Wagner JM, Dromerick AW, Sahrmann SA, Lang CE. Upper extremity muscle activation during recovery of reaching in subjects with post-stroke hemiparesis. Clin Neurophysiol. 2007;118(1):164-176; doi: 10.1016/j. clinph.2006.09.022.

7. Pauley T, Phadke CP, Kassam A, Ismail F, Boulias C, Devlin M. The influence of a concurrent cognitive task on lower limb reaction time among stroke survivors with right- or left-hemiplegia. Top Stroke Rehabil. 2015; 22(5):342-348; doi: 10.1179/1074935714Z.0000000041.

8. Pohl PS, McDowd JM, Filion D, Richards LG, Stiers W. Implicit learning of a motor skill after mild and moderate stroke. Clin Rehabil. 2006;20(3):246-253; doi: 10.1191/0269215506cr916oa.

9. Orrell AJ, Eves FF, Masters RSW, MacMahon KMM. Implicit sequence learning processes after unilateral stroke. Neuropsychol Rehabil. 2007;17(3):335-354; doi: 10.1080/09602010600832788.

10. Stewart JC, Dewanjee P, Shariff U, Cramer SC. Dorsal premotor activity and connectivity relate to action selection performance after stroke. Hum Brain Mapp. 2016;37(5):1816-1830; doi: 10.1002/hbm.23138. 
11. Lai S-M, Studenski S, Duncan PW, Perera S. Persisting consequences of stroke measured by the Stroke Impact Scale. Stroke. 2002;33(7):1840-1844; doi: 10.1161/01. str.0000019289.15440.f2.

12. Woods DL, Wyma JM, Yund EW, Herron TJ, Reed B. Factors influencing the latency of simple reaction time. Front Hum Neurosci. 2015;9:131; doi: 10.3389/fnhum. 2015.00131.

13. Lang CE, Lohse KR, Birkenmeier RL. Dose and timing in neurorehabilitation: prescribing motor therapy after stroke. Curr Opin Neurol. 2015;28(6):549-555; doi: 10.1097/WCO.0000000000000256.

14. Lin C-HJ, Winstein CJ, Fisher BE, Wu AD. Neural correlates of the contextual interference effect in motor learning: a transcranial magnetic stimulation investigation. J Mot Behav. 2010;42(4):223-232; doi: 10.1080/ 00222895.2010.492720.

15. Kal E, Winters M, van der Kamp J, Houdijk H, Groet E, van Bennekom $\mathrm{C}$, et al. Is implicit motor learning preserved after stroke? A systematic review with metaanalysis. PLoS One. 2016;11(12):e0166376; doi: 10.1371/ journal.pone.0166376.

16. Ashworth B. Preliminary trial of carisoprodol in multiple sclerosis. Practitioner. 1964;192:540-542.

17. Brucki SMD, Nitrini R, Caramelli P, Bertolucci PHF, Okamoto IH. Suggestions for utilization of the minimental state examination in Brazil [in Portuguese]. Arq Neuropsiquiatr. 2003;61(3B):777-781; doi: 10.1590/ s0004-282x2003000500014.

18. Folstein MF, Folstein SE, McHugh PR. "Mini-mental state”. A practical method for grading the cognitive state of patients for the clinician. J Psychiatr Res. 1975;12(3): 189-198; doi: 10.1016/0022-3956(75)90026-6.

19. Maki T, Quagliato EMAB, Cacho EWA, Paz LPS, Nascimento NH, Inoue MMEA, et al. Reliability study on the application of the Fugl-Meyer scale in Brazil. Braz J Phys Ther. 2006;10(2):177-183; doi: 10.1590/S141335552006000200007.

20. Bohannon RW, Smith MB. Interrater reliability of a modified Ashworth scale of muscle spasticity. Phys Ther. 1987;67(2):206-207; doi: 10.1093/ptj/67.2.206.

21. Hermens HJ, Freriks B, Disselhorst-Klug C, Rau G. Development of recommendations for SEMG sensors and sensor placement procedures. J Electromyogr Kinesiol. 2000;10(5):361-374; doi: 10.1016/s1050-6411(00)00 027-4.

22. Winstein CJ, Stein J, Arena R, Bates B, Cherney LR, Cramer SC, et al. Guidelines for adult stroke rehabilitation and recovery: a guideline for healthcare professionals from the American Heart Association/American Stroke Association. Stroke. 2016;47(6):e98-e169; doi: 10.1161/STR.0000000000000098.

23. Boyd LA, Quaney BM, Pohl PS, Winstein CJ. Learning implicitly: effects of task and severity after stroke. Neurorehabil Neural Repair. 2007;21(5):444-454; doi: $10.1177 / 1545968307300438$.
24. Cohen J. Statistical power analysis for the behavioral sciences. New York: Lawrence Erlbaum Associates; 1988.

25. De Paiva Silva FP, Sbeghen Ferreira de Freitas SM, da Silva Comenalle E, Alouche SR. Uncertainty in aiming movements and its association to hand function. Motriz Rev Educ Fis. 2015;21(3):222-229; doi: 10.1590/ S1980-65742015000300001.

26. Coqueiro PR, Sbeghen Ferreira de Freitas SM, Mendes Assunção e Silva C, Alouche SR. Effects of direction and index of difficulty on aiming movements after stroke. Behav Neurol. 2014;2014:909182; doi: 10.1155/2014/ 909182.

27. Bernhard CG, Bohm E. Monosynaptic corticospinal activation of fore limb motoneurones in monkeys (Macaca mulatta). Acta Physiol Scand. 1954;31(2-3):104-112; doi: 10.1111/j.1748-1716.1954.tb01118.x.

28. Merbah S, Meulemans T. Learning a motor skill: effects of blocked versus random practice. A review. Psychol Belg. 2011;51(1):15-48; doi: 10.5334/pb-51-1-15.

29. Schilder P. The image and appearance of the human body. New York: International University Press; 1950.

30. Ayres AJ. Development of body scheme in children. Am J Occup Ther. 1961;15:99-102.

31. Brunt D, Housner LD, McElroy J. Manipulation of dominant/non-dominant hand and ipsilateral/contralateral movement as a function of response organization in fourth grade children. Percept Mot Skills. 1983;56(1): 331-334; doi: 10.2466/pms.1983.56.1.331.

32. Klapp ST. Motor response programming during simple choice reaction time: the role of practice. J Exp Psychol Hum Percept Perform. 1995;21(5):1015-1027; doi: 10.1037/0096-1523.21.5.1015.

33. Janacsek K, Nemeth D. Implicit sequence learning and working memory: correlated or complicated? Cortex. 2013;49(8):2001-2006; doi: 10.1016/j.cortex.2013.02. 012.

34. Nepveu J-F, Thiel A, Tang A, Fung J, Lundbye-Jensen J, Boyd LA, et al. A single bout of high-intensity interval training improves motor skill retention in individuals with stroke. Neurorehabil Neural Repair. 2017;31(8): 726-735; doi: 10.1177/1545968317718269. 